\title{
JUVENTUDE DO CAMPO E POLÍTICAS PÚBLICAS: ALGUMAS REFLEXÕES DE UM TEXTO EM CONSTRUÇÃO
}

\author{
Rogério Nunes da Silva ${ }^{1}$, Maria Regina Clivati Capelo 2 \\ ${ }^{l}$ Rogério Nunes da Silva- licenciado em Ciências Sociais pela Universidade Estadual de Londrina- Membro do Grupo de Pesquisa \\ Catálogo de Juventudes: (re)conhecendo desigualdades e diversidades". Secretário Executivo da Comissão Pastoral da Terra, Londrina, \\ Paraná, Brasil. \\ ${ }^{2}$ Prfa. do Depto. De Ciências Sociais da UEL. Doutora em Educação pela UNICAMP.
}

\section{RESUMO}

Este artigo é fruto de um trabalho de pesquisa realizado no projeto" Catálogo de Juventudes: (re)conhecendo desigualdades e diversidades" sub- grupo de pesquisa de Juventude do Campo, que está sendo desenvolvido por um grupo interdisciplinar de professores e alunos da Universidade Estadual de Londrina. Objetivamos no presente artigo, ainda que de forma preliminar, mapear as diversas interpretações e conceitos acerca do campo brasileiro na atualidade. Outro foco de nossa análise tem a intenção de explicitar como as ciências modernas constroem a noção de juventude como uma categoria social, e como esta pode nos ajudar a pensar o campo e a juventude do campo na contemporaneidade. Por fim buscamos identificar quais são os focos de tensão enfrentados pelos jovens no campo e como as políticas públicas vêm atuando junto a esse segmento social.

Palavras-chave: Juventude, área rural, diversidade social, políticas públicas, juventude do campo.

\section{YOUTH OF RURAL AREAS AND PUBLIC POLICIES: SOME REFLECTIONS ON A TEXT IN CONSTRUCTION}

\begin{abstract}
This article is result of a research work of a subgroup of research on Youths of rural areas of the Project "Catalogue of Youths: $(\mathrm{Re})$ cognizing inequalities and diversities", which is being developed by an interdisciplinary group of professors and students of the State Unviersity of Londrina. The purpose of this paper is to map, even in a preliminary form, the several interpretations and concepts of present Brazilian rural areas. Another focus of our analysis intends to explain how modern sciences build the concept of youth as a social category and how this category can help us presently theorize about the rural area and the youth of rural areas. Finally we tried to identify which are the tensions faced by the youths of rural areas and how public policies are intervening in in this social segment.
\end{abstract}

Key Words: Youth, rural area, social diversity, public policies, youth of rural areas. 


\section{A SOCIOLOGIA E OS ESTUDOS DO CAMPO BRASILEIRO}

As mudanças nas estruturas produtivas ocorridas na sociedade ocidental na contemporaneidade acarretaram em rupturas e alterações nas instâncias sociais, assim se torna necessário confrontar as categorias analíticas presentes na sociologia (juventudecampo- cidade) para que possamos pensar a processualidade histórica.

Ao olharmos para o processo histórico brasileiro percebemos que 0 campo constitui-se em um espaço de embate e conflito. O desenvolvimento da sociedade nacional, engendrou, e forjou uma estrutura fundiária de características específicas no caso brasileiro. Vale a pena ressaltar que este processo não se constitui como homogêneo e linear, e que em nossa contemporaneidade, a problemática do campo ainda se coloca pautada nas discussões acadêmicas, políticas e sociais.

O campo se configurou como um espaço de pesquisa e reflexão para a sociologia brasileira. Historicamente a sociedade nacional teve no campo, um dos principais eixos de formação da identidade nacional. Esta preocupação de entender o campo brasileiro se explicita em diversos momentos ou obras importantes da produção sociológica nacional. Podemos apontar, mesmo que cada um a partir de sua perspectiva de análise, que as obras de Gilberto Freyre e seu livro Casa Grande e Senzala (1933), Sergio Buarque de Holanda e seu Raízes do Brasil (1936) e Caio Prado Júnior e sua grande análise contida na
Formação Do Brasil Contemporâneo(1942), têm como pano de fundo pensar a importância e o papel do campo na formação das estruturas políticas, sociais, econômicas e culturais do Brasil.

Celso Furtado nos aponta que a estrutura agrária brasileira apresenta-se com um dos problemas mais complexos de nossa economia agrária. A Compreensão do seu processo histórico nos permite identificar que a mesma se estrutura na grande propriedade privada, e esta tem um papel central no processo de ocupação do território brasileiro.

Para o economista, a empresa agrícola escravista se constituiu como uma célula matriz do tecido das instituições nacionais. $E$ a partir desta que se estruturou a economia e a sociedade brasileira. O processo de ocupação do território, e a formação da nossa sociedade foram conduzidos por homens economicamente poderosos que fizeram do controle da propriedade da terra instrumento de conservação do monopólio do poder. Essa relação entre grandes grupos econômicos e propriedade da terra inviabilizou a estruturação de comunidades agrícolas. Diante da dificuldade de acesso às melhores terras, a comercialização dos produtos e a concorrência com a mão-de-obra escrava tiveram o papel de abrir novas fronteiras agrícolas para a expansão dos grandes latifúndios, esta limitação da estruturação fundiária a partir da pequena propriedade. Com a pratica de uma agricultura itinerante, os pequenos agricultores desempenham a função de abrir os campos ou derrubar a mata para transformá-las em pasto.

$\mathrm{Na}$ década de 50 se inicia na agricultura brasileira o que se convencionou a denominar 
de processo de modernização tecnológica. O mesmo no Brasil, respirou os ares da revolução verde nos Estados Unidos. Esse processo de modernização, instituído pelo Estado a partir da década de 60 , mais especificamente com o golpe militar de 1964 , pode ser apontado como conservador, ou seja, se muda e tecnifica o processo produtivo agrícola, mas não se transforma a estrutura fundiária brasileira que historicamente se baseou na grande propriedade ${ }^{1}$.

É importante apontar que no pré-64 a sociedade brasileira debatia dois projetos antagônicos de desenvolvimento nacional: de um lado, o projeto apoiado pelos movimentos populares, que defendiam desenvolvimento com distribuição de renda e de outro lado, um projeto defendido pelas forças políticas mais conservadoras, com amplo apoio do capital internacional, que defendia 0 crescimento econômico, através da integração da economia brasileira com o Capital internacional, tendo como mote principal o crescimento econômico, em primeiro lugar, relegando a distribuição de renda lugar secundário.

No primeiro projeto, a agricultura e os trabalhadores rurais tinham um papel essencial, porque era vital a reforma agrária para a distribuição de renda. Através de uma

\footnotetext{
${ }^{1}$ Conforme dados do Incra, o Brasil continua sendo o país com um dos maiores índices de concentração da terra. As 27 propriedades de maior extensão se somadas atingem uma superfície igual a do Estado de São Paulo. A soma das 300 maiores propriedades forma a superfície do Estado de São Paulo e Paraná. Enquanto 2,4 milhões de imóveis que representam $57,6 \%$ das propriedades ocupam apenas $6 \%$ da área, correspondente a 26, 7 milhões de hectares. Na outra ponta os 70 mil imóveis que representam 1,7 das propriedades ocupam uma área de 183 milhões, ou seja, 43,8\% da área. In. REVERS, Isidoro. 2005.
}

reforma agrária ampla, massiva e sob o controle dos trabalhadores, cresceria a demanda interna, e esta impulsionaria a produção industrial e agrícola interna.

Para o segundo projeto, a Reforma agrária e a distribuição de renda não tinham nenhuma importância. O que era essencial era a abertura da economia brasileira aos capitais internacionais. Neste projeto, a agricultura deveria constituir-se em demandante de insumos industriais, químicos, mecânicos e biológicos. O mercado para a demanda desta produção crescente seria prioritariamente $\mathrm{o}$ mercado industrial externo: produzir para exportar.

Este movimento do capital na agricultura impôs novas formas de ocupação da fronteira agrícola, concentrou ainda mais a terra, a riqueza, a comercialização dos produtos agrícolas. Por outro lado, acelerou a expropriação e a expulsão dos trabalhadores, acelerando o processo de urbanização na sociedade brasileira, intensificou o fluxo migratório, consolidou o trabalho assalariado no campo e constitui-se no que hoje é chamado de agronegócio². (ALVES, 2005, P.4)

A década de 70 pode ser marcada pela influência dos estudos marxistas em torno do campo/rural na sociologia Estes procuraram romper com a concepção harmônica e idílica do espaço rural, característica marcante dos estudos funcionalistas das décadas de 30 a 60 .

\footnotetext{
2 Estamos chamando de agronegócio, o modelo de desenvolvimento agrícola atual, que ocupa longas extensões de terra principalmente com a monocultura da cana-de-açúcar, da soja e do milho, onde grandes empresas capitalistas (a maior parte delas estrangeiras) controlam o processo de produção, beneficiamento, industrialização e comercialização de produtos de origem agrícola, pecuária, florestal e extrativista, a maior parte destes produtos são produzidos tendo em vista o abastecimento do mercado internacional. Essas empresas envolvem diversos setores da economia que incluem desde a produção até as fontes de financiamento como os bancos privados e estatais, passando pela agroindústria e as empresas de comercialização. É um verdadeiro complexo empresarial que ganhou importância para os interesses do comércio exterior brasileiro
} 
A novidade trazida pelas análises marxistas se expressa na seguinte equação: para o viés marxista dos anos 70 o campo estaria fadado à extinção, ou seja, o processo de modernização da atividade produtiva, industrialização das propriedades rurais, e o conseqüente êxodo rural deste período, teria como um de seus resultados a "extinção do mundo rural" como universo diferenciado do "mundo urbano" (AMARAL, CAPELO, MANTOVANELLI., 2004, p.5)

\section{Para Abramovay (1998) o que} caracteriza o meio rural brasileiro é a presença da agricultura familiar enquanto unidade de produção. Segundo este a década de 80 pode ser caracterizada por uma interiorização industrial, esta forma uma combinação agroindustrial que trás consigo aumento da produtividade das unidades agrícolas. Para o mesmo, como conseqüência deste processo a uma capitalização da atividade agrícola e exclusão do pequeno lavrador. Um outro aspecto levantado por Abramovay é que este processo de capitalização da agricultura brasileira tencionou ainda mais os conflitos por terra no território nacional ${ }^{3}$.

Para Carneiro (2004)o rural vem sendo construído como negação do urbano. Diante

\footnotetext{
${ }^{3}$ Segundo dados da Comissão Pastoral da Terra existem hoje no Brasil aproximadamente $200 \mathrm{mil}$ famílias envolvidas em conflitos agrários, estas estão acampadas e/ou dentro das áreas por elas reivindicadas. Essas famílias estão nos diversos movimentos sociais de luta pela Terra. Só no Paraná no ano de 2004 foram registradas 45 ocupações de terra, envolvendo aproximadamente 5740 famílias. Essas ações no Paraná foram conduzidas por 10 movimentos sociais diferentes, esses dados nos mostram uma pluralidade de organizações no campo paranaense/brasileiro e que a bandeira da reforma agrária vem sendo defendida por um conjunto de movimentos sociais que extrapola as estruturas e o alcance do Movimento dos Trabalhadores(as) Rurais Sem Terra, como muitos acreditam.
}

deste modelo classificatório o "Brasil Rural" é visto por uma imagem distorcida (essa visão distorcida se traduz nos números da população rural brasileira-10 \%). Para a mesma há alguns problemas nesta classificação. A primeira se refere há não existência de divisões estruturais que nos permitam visualizar o que é "urbano" ou " rural", a segunda esta colocada na heterogeneidade regional e a multiplicidade de entendimentos do que seja " rural" ou " campo" na atualidade.

Stropasolas (2002) salienta que na sociologia a um grupo de autores e intelectuais que dedicam-se à análise das questões rurais. Para este, existe uma preponderância das análises que pautam-se na dicotomia cidade e campo. Apontamos para a necessidade de ultrapassar a dualidade campo/cidade evidenciada pelo autor citado. Assim entendemos que o campo é socialmente produzido, e que as análises do campo devem ultrapassar esta concepção dualista, onde campo/cidade se constituem em modelos de desenvolvimento antagônicos, espaços sociais que se contrapõem. O primeiro sinônimo do atraso, do que deve ser superado, já a segunda, explicitação do moderno e do avanço.

Acreditamos que pensar o campo na atualidade, é alargar nosso olhar, é fugir do debate restrito apenas as preocupações econômicas, ou seja, o campo não é sinônimo do agrícola, pois além da produção de gêneros alimentícios, o campo é lugar de reprodução de vida, de construção de relações sociais, de formação de identidades coletivas.

Ao olharmos para o campo brasileiro percebemos uma heterogeneidade de interpretações, conceitos e perspectivas 
colocadas a respeito do campo na contemporaneidade- está tendência também percebemos na sociologia, ou no que podemos chamar de sociologia rural. Um outro aspecto do campo brasileiro a nosso ver, é a heterogeneidade das vivencias sociais e dos grupos sociais/étnicos presente no campo. (são assalariados rurais, posseiros, pequenos produtores, extrativistas, indígenas, quilombolas).

Diante das diversas análises expostas sucintamente nos parágrafos anteriores identificamos, ainda que preliminarmente dois pressupostos teóricos e políticos no momento atual acerca do campo. O primeiro entende que o campo está fadado a "extinção", ou seja, o processo de industrialização/modernização da agricultura tornará homogêneo as vivências e as realidades sociais no campo. Nesta perspectiva de modelo agrícola o processo de mecanização, industrialização/modernização da atividade agrícola ( nas pequenas propriedades por meio das agroindústrias, mais prioritariamente nas grandes propriedades explicitado no agronegócio) é um elemento dinamizador da economia nacional, tendendo a expandir-se e ocupar cada vez menos mão-de-obra, este modelo vem fortalecendo-se e sendo priorizado pelo o investimento do poder público ${ }^{4}$.

A segunda perspectiva aponta que

\footnotetext{
${ }^{4}$ Este opção do poder público é evidente quando olhamos o montante de recurso destinado aos grandes produtores e aos pequenos produtores. Segundo dados da Comissão Pastoral da Terra, em 2005 o agronegócio receberá aproximadamente 39,5 bilhões de investimentos, enquanto que os pequenos produtores não receberam mais do que 7 bilhões.
}

mais um espaço de produção econômica/agrícola o campo se configura como um espaço social de construção de vivências, valores, enfim, de uma identidade social diferenciada do mundo urbano e que o processo de desenvolvimento agrícola atual, traduzido naquilo vem se denominando agronegócio é estritamente negativo a sociedade como um todo, pois gera um falso crescimento econômico(pois é financiado com o dinheiro público e a maioria da produção dos bens alimentares são produzidos nas pequenas propriedades) ${ }^{5}$, expulsa as famílias do espaço agrícola, viola o meio ambiente e as leis trabalhistas e ameaça a soberania nacional(pois o modelo agrícola atual é controlado pelas grandes empresas transnacionais).

Partimos do pressuposto que o campo deve ser pensando como um espaço de heterogeneidade social e econômica , no entanto, reconhecemos que esta heterogeneidade esta limitada dentro do modo capitalista de produção, ou seja, as relações de produção estão subordinadas ao interesse do capital.

Assim, no nosso entendimento torna-se necessário para pensar o campo na atualidade romper com a visão que reputa o atraso a este espaço, em contraponto da modernidade como característica do mundo urbano. Desta forma ainda que provisoriamente, para nós o conceito

\footnotetext{
${ }^{5}$ Dados do IBGE nos mostram que mais que um modelo agrícola o agronegócio é um fenômeno político e ideológico que mascara os dados da produtividade no Brasil. Conforme o instituto, 78,1\% da produção total de soja no país é proveniente de pequenos e médios agricultores. Outros produtos de consumo como ovos, café, feijão, milho, mandioca são em sua maioria oriundos de pequenos agricultores: os camponeses produzem mais de 77\% dos ovos $70,4 \%$ do café; $78,5 \%$ do feijão; $54,4 \%$ do milho; $91,9 \%$ da mandioca. Já a produção de horticultura e legumes é totalmente proveniente de pequenos agricultores.
} 
de campo, representa mais que um espaço de produção agrícola. Ao olharmos para o mesmo o enxergamos como o "campo de vida", de relações sociais, de luta pela terra, ou seja "[...] é muito mais do que aquele espaço geográfico que se situa além do perímetro urbano, é um espaço de possibilidades que ${ }^{6}$ dinamizam a tessitura de relações sociais" (AMARAL, CAPELO, MANTOVANELLI, 2004, p.5) forjando a construção de vivências sociais específicas e diferenciadas do mundo urbano.

Acreditamos que apesar das inúmeras transformações ocorridas na sociedade brasileira contemporânea, o campo ainda se coloca como um espaço que forja e nos ajuda a pensar as mudanças em curso na sociedade. Assim apesar da hipervalorização dos benefícios do mundo urbano (que em via de regra mascara os problemas e as contradições deste) o campo ainda se coloca como elemento formador e definidor de identidades coletivas.

\section{O CONCEITO DE JUVENTUDE}

Ao olharmos para a modernidade percebemos que esta constrói faixas etárias (infância- terceira idade), que não são apenas limites etários naturais, mas são também representações simbólicas e situações sociais. A sociedade moderna não é constituída apenas por estruturas de classe, mas também por faixas etárias e a cronologização do curso da vida que também

\footnotetext{
${ }^{6}$ DADOS POPULAÇÃO RURAL-URBANA
}

influenciaram na criação das instituições modernas(escola- estado). As faixas etárias reconhecidas e as categorias sociais que delas se originaram sofreram mudanças, alterações e supressões na modernidade. O período definido como de transição e ingresso na maturidade se materializou em 3 termos mais contundentes: juventude, adolescência e puberdade(GROPPO, 2000).

As ciências médicas criaram a concepção de puberdade para significar e explicar a fase de transformação no corpo do indivíduo. A psicologia e a psicanálise criaram a concepção de adolescência, para explicar o período correspondente às mudanças na personalidade e no comportamento. Para a sociologia a concepção de juventude é o período de interstício entre funções sociais da infância e as funções sociais do homem adulto.

Ao observamos a produção sociológica a respeito observamos que $o$ conceito de juventude vem se afirmando como uma categoria social. Assim descarta-se a possibilidade de definir por somente uma faixa etária específica, ou "classe de idade", ou ainda uma classe social. Ao tomarmos esta idéia do conceito de juventude como uma categoria social temos dois eixos norteadores: o primeiro aponta para a idéia que o conceito de juventude é uma representação sócio-cultural e o segundo que o mesmo também se configura como uma situação social, Groppo mostra isto ao afirmar que "a juventude é uma concepção, representação ou criação simbólica fabricada pelos grupos sociais ou pelos próprios indivíduos tidos como jovens, para significar uma série de comportamentos e atitudes a eles atribuídos". (GROPPO, 2000, p. 8) 
Rezende apud Groppo (2000) sugere o uso sociológico no plural do termo "JUVENTUDE", pois para o mesmo há uma diversidade na vivência desta fase de transição. Percebemos essa característica quando o mesmo afirma:

Esta concepção alerta-nos sobre a existência, na realidade dos projetos sociais concretos, de uma pluralidade de juventudes: de cada recorte sócio- cultural, classe social, estrato, etnia, religião, mundo urbano ou rural, gênero etcsaltam subcategoria de indivíduos jovens, com características, símbolos, comportamento, subculturas e sentimentos próprios. Cada juventude pode reinterpretar a sua maneira o que é "ser jovem", constratando-se não apenas em relação às crianças adultos, mas também em relação a outras juventudes" (GROPPO, 2000, p. 15)

Entendemos que a definição de juventude, apropriando-nos do referencial construído pelas ciências modernas, que as "juventudes" possuem a função social de "maturação" do indivíduo, ou seja, da socialização e integração do indivíduo à sociedade moderna e adulta, e que esse processo se processa de maneira heterogênea e diversificada, pois cada grupo juvenil cria e (re) cria identidades específicas.

Diante disto nos colocamos uma questão: Será que a elaboração de políticas públicas voltadas ao público juvenil no espaço do campo vem incorporando esta noção de diversidade juvenil, ou seja as políticas públicas no campo brasileiro visualizam e reafirmam que há um conjunto de jovens forjando uma identidade juvenil diferenciada do mundo urbano?

\section{Algumas considerações sobre a juventude do campo e os estudos dos jovens do campo na sociologia contemporânea.}

$\mathrm{Na}$ atualidade há um crescimento da atenção dirigida aos jovens no Brasil( meios de comunicação- poder público- sociedade civil) no que se refere aos meios de comunicação percebe-se a preponderância de dois eixos de tematizações: um primeiro voltado ao mercado de consumo e temas ligados a culturacomportamento e lazer juvenil e um segundo nos noticiários abordando temas ligados aos "problemas sociais'que afetam os jovens brasileiros.

$\mathrm{Na}$ academia crescem as dissertações de mestrado e teses de doutorado que tem como temática os jovens. Estes estudos em sua maioria, têm tido como enfoque discutir, analisar os sistemas e instituições presentes na vida dos jovens(escola- família) ou ainda as estruturas sociais que colocam os jovens em situações "problemáticas". No entanto, apesar do reconhecimento da diversidade dos grupos e vivências juvenis a maioria destes estudos se focam no urbano, sendo pouco expressivos as produções e reflexões acerca do "universo juvenil" no campo.

Mesmo diante da pouca atenção, e dos poucos estudos acerca dos jovens no espaço do campo encontramos algumas análises que tentam entender e explicar o contexto juvenil camponês. (ABRAMOVAY 1998) salienta que na atualidade visualizamos um conjunto de transformações no campo. Os grandes proprietários vêm ampliando as bases técnicas de produção, isto vem acarretando em um 
desemprego estrutural no campo, na esfera dos pequenos produtores percebe-se a emergência de novas formas de organização e articulação que visam garantir a permanência no campo. Um dos efeitos destas transformações ocorridas no universo camponês para o autor se evidencia na migração seletiva pautada na questão de gênero e faixa etária, a migração de jovens é mais acentuada, principalmente a migração feminina. Para o autor esse processo de migração seletiva que ocorre no campo se configura como uma de forma de reorganizar as relações familiares - pois em muitos casos a área de terra é pequena, assim uma repartição da propriedade que contemplasse todos os filhos(as) inviabilizaria o sustento familiar de todos(as) - e garantir a permanência dos pequenos no campo ${ }^{7}$.

Guigou (1968) ao pensar o contexto rural francês afirma que o conceito de "jovem"se refere mais que uma fase de transição, e propõe a seguinte tipificação: a existência de jovens rurais-agrícolas, estes seriam aqueles jovens que vivem e trabalham no campo, um segundo grupo na classificação proposta pelo autor são os operários rurais, ou seja, aqueles que trabalham na cidade e residem na vila rural. Para Guigou o critério etário não é suficiente para definir o jovem rural, faz-se necessário pensar a noção de pertencimento, analisar as

\footnotetext{
${ }^{7} \mathrm{Na}$ década de 1960 o grupo etário que migrava para as cidades tinha uma media de 40 a 49 anos, nos anos 1990 o grupo etário migrante passou a ter 15 a 19 anos. Sendo assim foi se configurando um mundo rural mais masculino e mais envelhecido. Os autores ressalvam as diferenças regionais, mostrando, por exemplo, que no Nordeste brasileiro há o menor grau de masculinização.
}

relações que estes jovens constroem com a sociedade mais ampla, para que assim possamos entender as continuidades $\mathrm{e}$ descontinuidades na formação da noção ser jovem no campo e do campo.

Para Stropassolas (2002, p.12) o desafio é compreender as ruralidades conforme as representações construídas pelos jovens, o mesmo aponta que o rural ainda é entendido como diferente do urbano, pois ao observar os jovens do oeste catarinense o autor evidencia que nas atividades cotidianas nesta região "o rural ainda é apresentado como diferente do urbano, com redes de sociabilidade que incluem o jogo de futebol como espaço masculino".

Carneiro (2004) novamente aponta para a existência de poucos estudos sobre o universo social e cultural dos jovens rurais, para a mesma o jovem no espaço do campo é olhado na maioria dos estudos a partir do espaço do trabalho familiar.

Segundo Durston apud Carneiro (2004), o olhar a partir da ótica do trabalho reforça a invisibilidade da juventude rural nas demais esferas da vida social, para o mesmo autor a categoria "JUVENTUDE RURAL" é fluída, imprecisa, variável e extremamente heterogênea. Ainda segundo o autor está invisibilidade pauta-se em um olhar baseado na compreensão urbana de juventude. No mundo urbano a noção de juventude se sustenta em dois eixos: o primeiro na visualização/existência de um espaço cultural propriamente juvenil e no adiamento das responsabilidades e dos papéis dos adultos. No campo tradicionalmente o jovem começa a trabalhar mais cedo em relação ao mundo urbano. Outro aspecto apontado pelo autor se refere à família. Os jovens no campo 
se constituem como chefe de família mais "precocemente" comparando com os jovens que residem na cidade. Diante destas duas premissas a sociedade entende, que "parece legítimo supor que no campo a juventude acabou antes de começar". A partir desta evidencia conclui o autor, a juventude rural não é foco de atenção de projetos e políticas de combate à pobreza e desenvolvimento rural.

Carneiro (2004) sinaliza que há uma dificuldade em delimitar o que se designa como "JUVENTUDE RURAL" - para a mesma esta é uma categoria socialmente construída, que se caracteriza pela transitoriedade, outro ponto limitador está pautado na imprecisão do que se entende por rural, num contexto de intensificação dos universos do campo e da cidade. $O$ debate no meio acadêmico segundo a autora vem apontando para a necessidade de ampliar a definição do rural para além do setor agrícola., esse novo rural para a mesma inclui um número cada vez mais diversificado de ocupações- o que the mereceu o rótulo do "novo rural", e é resultado de processos recentes que têm transformado o mundo rural em um espaço cada vez mais heterogêneo e diversificado. "Contudo, devemos admitir que esse "novo" nem sempre significa uma melhoria na qualidade de vida no conjunto da população rural e nem pode ser entendido como um fenômeno generalizado no país" (CARNEIRO, 2004, p.245).

Neste contexto de transformações no campo percebemos que a juventude é a faixa demográfica mais afetada por essa dinâmica que tem reduzido perspectivas de trabalho na agricultura e concomitantemente tem aumentado referências do padrão de consumo(novas necessidades).

No entanto, reconhecemos que mesmo diante destas transformações na estrutura produtiva que reduz as possibilidade de trabalho na agricultura, existe ainda no campo uma enorme diversidade juvenil na atualidade (de gênero- escolaridade- condição econômica). Isso nos remete para impossibilidade de pensar um perfil da " juventude do campo " ou um tipo ideal do " jovem campo". Assim a formulação de políticas públicas direcionadas ao jovem no campo deve contemplar esta diversidade, ou seja, os desafios enfrentados pelos jovens no campo não se restringem ao acesso a terra, ou a criação de políticas de financiamento agrícola específicas aos jovens camponeses. Pensar políticas públicas tendo como foco os grupos juvenis camponeses significa entender que estes desenvolvem diversas relações com a terra e com a atividade agrícola.

\section{Juventude no campo na contemporaneidade e o desafio de construir políticas públicas específicas ${ }^{8}$.}

No Brasil atualmente são aproximadamente

\footnotetext{
${ }^{8}$ Optamos por manter o conceito usado pelos autores na fonte original. Assim em diversos momentos encontraremos as expressões Juventude Rural e Juventude do Campo, Rural e Campo. Como opção conceitual preferimos o conceito de campo e juventude do campo, pois para nós o conceito de campo nos possibilita abranger todas as situações que estão presentes no mundo rural, bem como para fugir da armadilha que considera $o$ rural como espaço exclusivo da agricultura ou da pecuária em oposição à modernidade industrial do urbano. Essa oposição não satisfaz a necessidade de compreender o campo em toda a sua complexidade e diversidade. No entanto, reconhecemos que há uma diversidade conceitual e de entendimentos sobre o campo na atualidade.
} 
34 milhões de brasileiros jovens, na faixa etária dos 15 a 24 anos. Diante deste contexto e contingente de jovens percebemos uma crescente preocupação por parte do poder público em desenvolver políticas e programas específicos a este grupo social.

Para Abramo (1997) as políticas e os programas desenvolvidos pelas instituições dividem-se em 2 blocos: no primeiro bloco se enquadram os programas de ressocialização, - segundo bloco é evidenciado pelos programas de capacitação profissional. Para a autora estes dois modelos de ação junto aos jovens visam intervir nas dificuldades de integração social (contenção do risco). A mesma salienta que os programas são falhos, pois passam longe de entender de forma ampla e aprofundada o universo juvenil.

A contemporaneidade apresenta como traço marcante à experiência de diversas vivências juvenis em grupos concretos que têm como papel forjar e criar as identidades juvenis. Essa diversidade se apresenta no aspecto econômico, social, étnico e geográfico. No entanto, apesar desta heterogeneidade juvenil são poucos os estudos, as políticas públicas que vêm procurando explicitar e contemplar em sua ação o universo juvenil construído no espaço do campo brasileiro.

Nos poucos estudos realizados, uma das questões que têm recebido atenção especial é o desejo dos jovens de permanecerem no campo e as condições de realização desse desejo. Segundo dados da pesquisa "Perfil da Juventude Brasileira",
${ }^{9}$ três assuntos mais interessam os jovens rurais: são eles emprego, cultura e lazer

Os números da pesquisa confirmam conclusões das pesquisas qualitativas que apontam que a educação se coloca como um importante instrumento visualizado pelos jovens para o acesso a uma ocupação bem remunerada e menos penosa que a agricultura, assim a educação é vista pelo enfoque do acesso ao mundo trabalho.Diante disso, visualizamos que também no meio rural o estudo é encarado como condição de ascensão social- "ser alguém na vida", o que no olhar de muitos jovens camponeses, essa "melhoria na qualidade de vida significa não ser agricultor".

Do total de jovens rurais que trabalham ou já trabalharam (66\%), mais da metade $(37 \%)$ estão vinculados ao mercado de trabalho na cidade, estes números indicam uma ausência de alternativa de emprego no meio rural.

Esta visualização do potencial da escolarização como meio de "mudar de vida" pode ser questionada quando olhamos para os dados da escolaridade. Sobre escolaridade a pesquisa conclui que entre os jovens rurais de hoje apenas $1 \%$ deles não estudou, enquanto $60 \%$ dos seus pais não estudaram ou fizeram até a $4^{\text {a }}$. série. Para Carneiro(2004) "o grande gargalo parece se localizar na idade em que o jovem começa a ser definido socialmente como 'trabalhador' em potencial, esperando-se, então, que ele contribua para aumentar a renda da família" (p. 249). Isto explica por que entre os $60 \%$ que freqüentaram o ensino fundamental, apenas $14 \%$ concluíram a $8^{\mathrm{a}}$. série. A autora

\footnotetext{
${ }^{9}$ Salientamos que todos os dados sobre a realidade da juventude rural presentes na pesquisa " Perfil da Juventude Brasileira" citados neste artigo têm como fonte o artigo de CARNEIRO 2004.
} 
soma-se a muitos outros pesquisadores ${ }^{10}$ que destacam a valorização social da educação escolar como condição de melhoria de vida para os jovens rurais.

Um primeiro desafio colocado às políticas que têm como foco os jovens camponeses tem como pauta a educação. É evidente a importância das instituições escolares nos projetos de vida pessoal destes (segundo dados da pesquisa " Perfil da Juventude Brasileira a maioria dos jovens rurais considera a escola importante para o futuro profissional- $95 \%)^{11}$. A escola também é um importante espaço de sociabilidade. No entanto, a escolarização na maioria dos casos é um primeiro passo para deixar de ser agricultor(a). Assim ao nosso ver, é de extrema importância a ampliação do sistema escolar no campo, e em todos os níveis de ensino, para que os jovens possam ter a oportunidade de conciliar o acesso a educação a vivência no seu espaço de origem e a atividade agrícola.

Um outro desafio referente à educação esta centrado no aspecto pedagógicocurricular. Os currículos escolares em sua maioria não refletem ou contribuem para que os jovens camponeses reflitam sobre o seu espaço de vida. Em sua grande maioria, os

\footnotetext{
${ }^{10}$ Ver : DEMARTINI (1979), ABRAMOVAY e outros (1998); CARNEIRO (1998); SILVESTRO e outros (2001); PEREIRA (2004).

${ }^{11}$ Esses números se aproximam bastante dos jovens residentes na cidade, isto é um indicativo das que apesar das especificidades, há semelhanças entre o universo cultural dos jovens do campo e da cidade, percebemos isto quando (CARNEIRO, 2004, p.260) salienta: "nesse sentido, diríamos que a juventude, "rural" e " urbana", estaria sendo afetada pela mesma ordem de problemas própria de uma sociedade ao mesmo tempo globalizada e subdesenvolvida. No entanto, entender a maneira como os jovens reagem e se adaptam a essa realidade exige levar em conta os que os diferencia
}

matérias didáticos, a organização curricular, e o quadro de professores(as) são estritamente urbanocêntricos, não considerando a especificidade do universo social/étnica e cultural camponês.

Um segundo ponto que apontamos é a questão do trabalho na agricultura. Tradicionalmente na organização familiar do trabalho não há individualização da renda. No entanto tem se observado a tendência de remuneração do jovem agricultor como mecanismo mantê-lo por mais tempo engajado no trabalho familiar e como conseqüência da própria pressão dos jovens. Outro aspecto visualizado é o aumento das opções de trabalho/emprego no campo fora da atividade agrícola, percebemos que este movimento se apresenta como uma alternativa aos jovens que desejam continuar vivendo em sua comunidade de origem. Com isso se torna primordial para que os jovens camponeses permaneçam no campo e não somente na atividade agrícola, a ampliação de políticas públicas que potencializam as alternativas de geração de trabalho e renda para os jovens em atividades agrícolas ou não agrícolas, para que os mesmo possam ter a possibilidade de acesso aos bens matérias/culturais/educacionais produzidos na contemporaneidade sem ter que deixar o campo.

Outras duas questões importantes que devem ser foco de políticas públicas, e que tencionam as relações familiares/produtivas no campo, interferindo na permanência- ou na migração para a cidade é a questão sucessória na unidade familiar e a de gênero. Stropassolas (2002) identifica que o processo migratório do

segundo os variados contextos sociais, econômicos e culturais" 
campo para a cidade na atualidade tem dois pontos mais agudos: o primeiro se refere a questão geracional, ou seja, ou jovens migram mais para a cidade que as outras faixas etárias, a segunda esta centrada na questão de gênero, este fluxo migratório é mais intenso quando olhamos para as moças do campo.

Assim, de forma paradoxal o sistema patriarcal camponês (ao privar os jovens do espaço de decisão na unidade familiar e ao preterir as jovens camponesas do processo sucessório-partilha da terra, relegando a estas exclusivamente o universo doméstico) tende ampliar as opções dos(as) jovens(as) camponeses para além da agricultura.

Entendemos, portanto, que é urgente desenvolver uma política de reforma agrária massiva e inclusiva, pautada não na lógica do mercado, onde o governo atua como agente comprador de terra, mas sim em um processo de desapropriação das terras grilhadas, dos latifúndios improdutivos, das terra devolutas. A nosso ver esse processo de desconcentração fundiária e distribuição de terra atenuariam os problemas sucessórios no interior das famílias camponesas, pois possibilitaria aos jovens que querem continuar na sua função de agricultor ter um espaço de terra condizente com suas necessidades básicas. Um outro ponto fundamental que deve ser pautado pelas políticas públicas no campo se refere às políticas específicas as mulheres, estas devem ser subsidiadas para assumir cada vez os espaços de decisão na unidade familiar agrícola, rompendo com as cercas e amarras impostas pelo espaço doméstico que tanto as oprime.

Finalizando reafirmamos que a construção de políticas públicas direcionadas aos jovens do campo têm como desafio reconhecer e atender os mesmos a partir da diversidade juvenil (pois são várias formas de ser jovens no campoassalariados rurais- agricultores familiaresindígenas- quilombolas- posseiros), que é inerente a juventude na contemporaneidade.

No entanto, quando apontamos para a importância da diversidade juvenil presente no campo, não estamos nos esquecendo do conjunto de desigualdades e discriminações presentes na sociedade atual (condição econômica, gênero, etnia). Assim diversidade não é sinônimo de desigualdade como defendem e entendem os Neoliberais. Também não estamos engrossando o discurso pós-moderno presente nas ciências modernas, partilhamos da afirmação de Capelo (2005) quando a mesma aponta para as armadilhas presentes na construção pós-moderna ao afirmar "ao ressaltar diferenças, desigualdades e complexidades do mundo rural, não queremos também nos tornar presas fáceis do relativismo pós-moderno que tudo admite, entretanto NADA É, de fato"

Assim, terminamos este texto com a certeza de que o investimento no campo por meio de políticas públicas (tendo como foco destas políticas os pequenos produtores(as) rurais- ampliação e efetivação dos direitos dos assalariados rurais) se constitui na atualidade como uma alternativa viável e necessária a sociedade brasileira de enfrentamento dos nossos problemas sociais. Acreditamos também que só haverá esperança de reprodução da vida dos nossos jovens(as) no campo brasileiro com uma mudança de opção de modelo agrícola nas 
nossas esferas governamentais, ou seja, dentro do modelo agrícola agressivo, exclusivamente exportador e economicista traduzido pela expressão agronegócio e apoiados pelos nossos governos, não há horizonte e perspectivas a juventude do campo.

\section{REFERÊNCIAS BIBLIOGRÁFICAS}

ABRAMO, Helena Wendel. Considerações sobre a tematização social da juventude no Brasil. Revista Brasileira de Educação. № 5 mai-jun-jul. 1997.

ABRAMOVAY, Ricardo. (Coord); SILVESTRO, $\mathrm{M}$; CORTINA, N; BALDISSERA, Ivan T; FERRARI D; TESTA, V. M. Juventude e agricultura familiar: desafios dos novos padrões sucessórios. Brasília: UNESCO, 1998.

ALVES, Francisco. Relatório /I Encontro Nacional da CPT sobre o setor sucroalcooleiro. 25 a 27 de fevereiro de 2005. Londrina- Paraná.

AMARAL, Wagner Roberto ; CAPELO, Maria Regina Clivati ; MANTOVANELLI, Thais Regina. Jovens Rurais ou Jovens do Campo: Primeiras aproximações. Londrina: UEL, 2004. (Texto para básico para discussão)

CARNEIRO, Maria José. Juventude Rural: projetos e valores. In: ABRAMO, H. W; BRANCO, P.P. Martoni (orgs). Retratos da juventude brasileira. SP: Instituto Cidadania: Editora da Fundação Perseu Abramo, 2005.
CONFLITOS NO CAMPO- Brasil 2004. Comissão Pastoral da Terra, Coordenação Nacional. Goiânia 2004.

DURSTON, J. Juventude rural, modernidade e democracia: desafio para os noventa. Juventude e desenvolvimento rural no Cone Sul LatinoAmericano. Série documentos temáticos. Brasil, RS, jun.

GROPPO, Luis Antonio. Juventude: ensaios sobre a sociologia e história das juventudes modernas. Rio de Janeiro: DIFEL, 2000.

GUIGOU, Jacques. Problemas de uma Sociologia da Juventude Rural. In: BRITTO, Sulamita de (Org), V. 2, Sociologia da Juventude. Rio de Janeiro: Zahar, 1968.

REZENDE, Cláudia Barcellos. Identidade. O que é ser jovem?. Revista Tempo e Presença,n.240, CEDI, 1989, pp. 4-5.

STROPASSOLAS, Valmir Luiz. O mundo rural no horizonte dos jovens: o caso dos filhos(as) de agricultores familiares de Ouro/SC. Tese de Doutorado. Santa Catarina: Centro de Filosofia e Ciências Humanas: UFSC, 2002.

REVERS, Isidoro. O eixo terra. In. Comissão Pastoral da Terra- Texto Base do II Congresso Nacional da Comissão Pastoral da Terra. Goiânia. 2005 